\title{
Situação das bibliotecas escolares no Brasil: o que sabemos?
}

\author{
Situation of school libraries in Brazil: what do we know?
}

Bernadete Santos Campello
Doutora em Ciência da Informação pela Universidade Federal de Minas Gerais - UFMG. Professora titular da Escola de Ciência da Informação da UFMG.

E-mail: campello@eci.ufmg.br

Paulo da Terra Caldeira

Mestre em Ciência da Informação pelo Instituto Brasileiro de Informação em Ciência e Tecnologia - IBICT. Professor adjunto da Escola de Ciência da Informação da UFMG.

E-mail: terra@eci.ufmg.br

Maura Alvarenga

Bolsista de Iniciação Científica (CNPq)

E-mail: maura_de_alvarenga@yahoo.com.br

Laura Valladares de Oliveira Soares

Bolsista voluntária

E-mail: laurinhavalladaresbr@gmail.com

\section{Resumo}

Este estudo teve como objetivo conhecer as características de diagnósticos sobre bibliotecas escolares brasileiras, elaborados por diversos autores. Foram identificados e analisados dezoito diagnósticos publicados na literatura da área, de 1979 a 2011, de forma a se obter uma visão do que já se estudou e se conhece a respeito das condições das bibliotecas escolares brasileiras. Foram analisados: os objetivos dos diagnósticos, a metodologia utilizada e a técnica de coleta de dados, o referencial teórico, os resultados obtidos, as conclusões e recomendações feitas pelos autores. A variedade de procedimentos de coleta e análise dos dados utilizados em cada diagnóstico impossibilitou inferências e conclusões mais aprofundadas. No conjunto, esses trabalhos compõem um retrato parcial da biblioteca escolar no país, confirmando a situação precária dessas instituições e tornando mais visíveis os problemas existentes.

Palavras-chave: Bibliotecas escolares. Diagnósticos. Brasil.

\begin{abstract}
This study aims to evaluate the characteristics of Brazilian school libraries surveys, produced by various authors from 1979 to 2011. Analysis was made of eighteen published surveys, in order to get a view of what has already been studied and is known regarding the conditions of Brazilian school libraries. Analysis was made of: the objectives of the surveys, the methodologies and data collection techniques, the theoretical approach, the results obtained and the conclusions and recommendations made by the authors. The variety of procedures for collecting and analyzing data used in each survey precludes inferences and conclusions. However, taken together, these studies constitute a partial picture of school libraries in the country, confirming the precarious situation of these institutions and making more visible the problems they face.
\end{abstract}

Keywords: School libraries. Surveys. 


\section{Introdução}

A literatura sobre biblioteca escolar no Brasil é pródiga em apontar a precariedade desta instituição nas escolas do país (VIANNA, CARVALHO, SILVA, 2004). Em tom indignado, muitos dos textos ressaltam a importância da biblioteca escolar e, ao mesmo tempo, chamam atenção para suas fragilidades e deficiências, exortando os responsáveis a tomar providências para mudar a situação. Esse "sentimento" de precariedade começou a se concretizar com a publicação de um estudo em 1979, nos anais do $10^{\circ}$ Congresso Brasileiro de Biblioteconomia e Documentação. O estudo, denominado Avaliação das bibliotecas escolares de $1^{\circ}$ grau na cidade de Londrina, averiguou a situação "real" de 20 bibliotecas de escolas da rede pública estadual daquele município e confirmou as condições precárias em que funcionavam, concluindo que "Na realidade, a maioria não passa de um 'depósito de livros' longe de cumprir os objetivos estabelecidos pela Biblioteconomia" (CRUZ, 1979, p. 848). Desde então, para suprir a necessidade de estudos "menos intuitivos" (CARVALHO, 1884, p. 21) foram realizados outros diagnósticos que levantaram dados de bibliotecas escolares em diversas regiões e municípios do país. Dezoito desses diagnósticos foram identificados na literatura da área (ver ANEXO 1), sendo sete artigos de periódico, cinco trabalhos apresentados em evento, quatro dissertações de mestrado e duas teses de doutorado. Algumas características desses diagnósticos (forma de publicação, origem institucional dos autores, âmbito geográfico, vinculação e número de bibliotecas estudadas) são apresentadas em ordem cronológica no QUAD. 1. A primeira coluna identifica o primeiro autor do diagnóstico, pelo qual ele será identificado ao longo do presente trabalho. 


\section{QUADRO 1 - Características gerais dos diagnósticos}

\begin{tabular}{|c|c|c|c|c|c|c|}
\hline $\begin{array}{l}\text { Diagnóstico } \\
\left(1^{\circ} \text { autor }\right)\end{array}$ & $\begin{array}{c}\text { Ano de } \\
\text { publicação }\end{array}$ & $\begin{array}{c}\text { Forma de } \\
\text { publicação }\end{array}$ & $\begin{array}{l}\text { Origem institucional } \\
\text { dos autores }\end{array}$ & $\begin{array}{c}\text { Âmbito } \\
\text { geográfico }\end{array}$ & $\begin{array}{c}\text { Vinculação das } \\
\text { bibliotecas } \\
\text { estudadas }\end{array}$ & $\begin{array}{c}\mathrm{N}^{\circ} \text { de } \\
\text { bibliotecas } \\
\text { estudadas }\end{array}$ \\
\hline CRUZ & 1979 & $\begin{array}{l}\text { Trabalho de } \\
\text { evento }\end{array}$ & $\begin{array}{c}\text { Universidade } \\
\text { Estadual } \\
\text { de Londrina }\end{array}$ & $\begin{array}{l}\text { Londrina, } \\
\text { PR }\end{array}$ & $\begin{array}{l}\text { Públicas } \\
\text { Estaduais }\end{array}$ & 30 \\
\hline $\mathrm{ACB}$ & 1981 & $\begin{array}{l}\text { Trabalho de } \\
\text { evento }\end{array}$ & $\begin{array}{c}\text { ACB - Associação } \\
\text { Catarinense de } \\
\text { Bibliotecários }\end{array}$ & $\begin{array}{c}\text { Florianópolis, } \\
\text { SC }\end{array}$ & $\begin{array}{l}\text { Públicas (15) } \\
\text { Particulares (8) }\end{array}$ & 23 \\
\hline MARTINS & 1983 & Dissertação & $\begin{array}{c}\text { Universidade Federal } \\
\text { da Paraíba }\end{array}$ & $\begin{array}{c}\text { João Pessoa, } \\
\text { PB }\end{array}$ & $\begin{array}{c}\text { Públicas (8) } \\
\text { Particulares (7) }\end{array}$ & 15 \\
\hline CARVALHO & 1984 & Tese $^{1}$ & $\begin{array}{c}\text { Universidade Federal } \\
\text { da Paraíba }\end{array}$ & $\begin{array}{l}\text { Fortaleza, } \\
\quad \text { CE }\end{array}$ & $\begin{array}{c}\text { Públicas } \\
\text { Estaduais (36) } \\
\text { Particulares (53) }\end{array}$ & 89 \\
\hline MADUREIRA & 1985 & Dissertação $^{2}$ & PUC-Campinas & $\begin{array}{c}\text { Paraná } \\
\text { (diversos } \\
\text { municípios) }\end{array}$ & $\begin{array}{l}\text { Públicas } \\
\text { Estaduais }\end{array}$ & $632^{3}$ \\
\hline QUEIROZ & 1985 & Dissertação & $\begin{array}{c}\text { Universidade Federal } \\
\text { de Minas Gerais }\end{array}$ & $\begin{array}{c}\text { Grande Vitória, } \\
\text { ES }\end{array}$ & $\begin{array}{l}\text { Públicas } \\
\text { Estaduais }\end{array}$ & 22 \\
\hline CUARTAS & 1987 & $\begin{array}{l}\text { Artigo de } \\
\text { periódico }\end{array}$ & $\begin{array}{l}\text { Universidade do } \\
\text { Rio Grande }\end{array}$ & $\begin{array}{c}\text { Rio Grande e } \\
\text { Santa Vitória } \\
\text { do Palmar, RS }\end{array}$ & $\begin{array}{l}\text { Públicas } \\
\text { Estaduais }\end{array}$ & 24 \\
\hline MAYRINK & 1991 & Tese & $\begin{array}{l}\text { Universidade de } \\
\text { São Paulo }\end{array}$ & $\begin{array}{l}\text { Microrregião } \\
\text { Alta Paulista, } \\
\text { SP (sete } \\
\text { cidades) }\end{array}$ & $\begin{array}{c}\text { Públicas (12) } \\
\text { Particulares (6) }\end{array}$ & 18 \\
\hline BARBOZA & 1991 & $\begin{array}{l}\text { Trabalho de } \\
\text { evento }\end{array}$ & $\begin{array}{c}\text { Universidade Federal } \\
\text { de Pernambuco }\end{array}$ & Recife, PE & Particulares & 17 \\
\hline BARROS & 1998 & Dissertação & $\begin{array}{c}\text { Universidade Federal } \\
\text { da Paraíba }\end{array}$ & Recife, PE & Públicas & 15 \\
\hline DUARTE & 1998 & $\begin{array}{l}\text { Artigo de } \\
\text { periódico }\end{array}$ & $\begin{array}{c}\text { Universidade Federal } \\
\text { da Paraíba }\end{array}$ & $\begin{array}{c}\text { João Pessoa, } \\
\text { PB }\end{array}$ & $\begin{array}{c}\text { Públicas } \\
\text { Estaduais (17) } \\
\text { Particulares (24) }\end{array}$ & 41 \\
\hline MARTUCCI & 1999 & $\begin{array}{l}\text { Artigo de } \\
\text { periódico }\end{array}$ & $\begin{array}{l}\text { Universidade Federal } \\
\text { de São Carlos }\end{array}$ & São Carlos, SP & $\begin{array}{l}\text { Públicas } \\
\text { Estaduais }\end{array}$ & $\begin{array}{c}18(\mathrm{em} \\
\text { atividade }) \\
8 \text { (desativadas) }\end{array}$ \\
\hline PERUCCHI & 1999 & $\begin{array}{l}\text { Artigo de } \\
\text { periódico }\end{array}$ & $\begin{array}{l}\text { Escola Agrotécnica } \\
\text { Federal de Sombrio }\end{array}$ & Criciúma, SC & $\begin{array}{c}\text { Públicas } \\
\text { Municipais }\end{array}$ & 4 \\
\hline $\begin{array}{l}\text { MACIEL } \\
\text { FILHO }\end{array}$ & 2001 & $\begin{array}{l}\text { Artigo de } \\
\text { periódico }\end{array}$ & $\begin{array}{c}\text { Universidade } \\
\text { Federal } \\
\text { de Pernambuco }\end{array}$ & $\begin{array}{l}\text { Pernambuco } \\
\text { (treze } \\
\text { municípios) }\end{array}$ & $\begin{array}{c}\text { Públicas e } \\
\text { Particulares (não } \\
\text { especifica o } \\
\text { número) }\end{array}$ & 114 \\
\hline ABREU & 2002 & $\begin{array}{l}\text { Trabalho de } \\
\text { evento }\end{array}$ & $\begin{array}{l}\text { Universidade Federal } \\
\text { de Minas Gerais }\end{array}$ & $\begin{array}{l}\text { Belo Horizonte, } \\
\text { MG }\end{array}$ & $\begin{array}{l}\text { Públicas } \\
\text { Estaduais }\end{array}$ & 153 \\
\hline ABREU & 2004 & $\begin{array}{l}\text { Artigo de } \\
\text { periódico }\end{array}$ & $\begin{array}{l}\text { Universidade Federal } \\
\text { de Minas Gerais }\end{array}$ & $\begin{array}{l}\text { Belo Horizonte, } \\
\text { MG }\end{array}$ & $\begin{array}{l}\text { Públicas } \\
\text { Estaduais }\end{array}$ & 63 \\
\hline NASCIMENTO & 2007 & $\begin{array}{l}\text { Artigo de } \\
\text { periódico }\end{array}$ & $\begin{array}{l}\text { Universidade de } \\
\text { São Paulo }\end{array}$ & $\begin{array}{l}\text { Ribeirão Preto, } \\
\text { SP }\end{array}$ & $\begin{array}{l}\text { Públicas } \\
\text { Estaduais }\end{array}$ & 8 \\
\hline MARTINS & 2011 & $\begin{array}{l}\text { Trabalho de } \\
\text { evento }\end{array}$ & $\begin{array}{c}\text { Prefeitura Municipal } \\
\text { de São José dos } \\
\text { Pinhais } \\
\end{array}$ & $\begin{array}{l}\text { São José dos } \\
\text { Pinhais, PR }\end{array}$ & $\begin{array}{l}\text { Públicas } \\
\text { Municipais }\end{array}$ & 71 \\
\hline
\end{tabular}

\footnotetext{
${ }^{1}$ Publicada posteriormente como livro: CARVALHO, A. M. S. A biblioteca na escola. Fortaleza: SESI/SENAI, 1984.

${ }^{2}$ Publicada posteriormente como artigo de periódico: MADUREIRA, M. A. E. A biblioteca escolar na rede estadual de ensino de $1^{\circ}$ grau do Paraná: diagnóstico e avaliação. Cadernos do CED, v. 4, p. 113-127, 1987.

${ }^{3}$ Nesse diagnóstico foram feitas visitas de observação a 34 escolas, das quais 26 tinham bibliotecas em funcionamento. Não é mencionado, entretanto, se as bibliotecas visitadas estão entre as 632 que responderam ao questionário.
} 
Os diagnósticos foram publicados entre 1979 e 2011, sendo quinze deles como trabalhos acadêmicos e três como iniciativas de bibliotecários. Foram estudadas, no total, 1365 bibliotecas. Excluindo-se as 114 do estudo de Maciel Filho (que não mencionou a vinculação administrativa das escolas), das 1251 restantes, 1136 pertencem a escolas públicas e 115 a escolas particulares ${ }^{4}$. Os diagnósticos cobriram as regiões Nordeste (seis diagnósticos), Sudeste (sete) e Sul (cinco). Cinco abrangeram mais de um município, mas a maioria (catorze) estudou bibliotecas de apenas um município, sendo que sete pesquisaram bibliotecas de capitais dos Estados (Florianópolis, Fortaleza, Vitória, Recife, João Pessoa, Belo Horizonte). Os dezoito diagnósticos coletaram dados sobre diversas características de bibliotecas escolares e, embora esses dados não permitam comparações, no seu conjunto delineiam a situação de um número significativo de bibliotecas escolares do país e podem constituir ponto de partida para estudos mais abrangentes e completos.

\section{Objetivo e metodologia}

O presente estudo pretende analisar esses diagnósticos, de forma a proporcionar uma visão do que já se estudou e se conhece a respeito das condições das bibliotecas escolares brasileiras. Os dezoito diagnósticos acima identificados e listados no ANEXO 1 formam o corpus de análise do presente estudo. Nesta análise, buscou-se identificar:

a) Os objetivos dos diagnósticos;

b) A metodologia utilizada e a técnica de coleta de dados;

c) O referencial teórico;

d) Os resultados obtidos;

e) As conclusões e recomendações feitas pelos autores.

\section{O que revelam os diagnósticos}

Nesta parte analisam-se os objetivos pretendidos pelos diagnósticos, a metodologia utilizada e o referencial teórico em que se embasaram e, também, os resultados referentes ao espaço físico, ao acervo, ao pessoal e aos serviços e atividades. Além disso, faz-se uma

\footnotetext{
${ }^{4}$ Considerando-se que as 63 bibliotecas do diagnóstico de Abreu (2004) estão incluídas no diagnóstico anterior da mesma autora (2002) e que houve dois diagnósticos realizados em João Pessoa, PB (MARTINS, 1983 e DURTE, 1998), estes números são, na realidade, ligeiramente menores.
} 
síntese das conclusões e recomendações apresentadas pelos autores.

\subsection{O que pretendiam alcançar}

Todos os diagnósticos, em maior ou menor grau, tiveram como objetivo coletar e analisar dados quantitativos e/ou qualitativos do que chamaram a "situação real" ou "condições de funcionamento" das bibliotecas. Tais dados dizem respeito, em sua maioria, a: recursos humanos, acervo, serviços oferecidos, espaço físico, mobiliário, aspectos administrativos e financeiros e comunidade de usuários das bibliotecas. Alguns diagnósticos, além da análise de dados quantitativos referentes a esses aspectos, tiveram objetivos mais amplos, como por exemplo:

"Caracterização da ação do bibliotecário escolar..." (MARTINS, 1983, p. 69).

"Avaliar a adequação do acervo tanto na quantidade quanto na qualidade e avaliar o desempenho dos recursos humanos" (CARVALHO, 1984, p. 49).

“... detectar os efeitos de um programa de treinamento para professores que atuam em bibliotecas escolares de $1^{\circ}$ e $2^{\circ}$ graus e exibição de audiovisual para treinamento de usuários de bibliotecas escolares" (CUARTAS, 1987, p. 9).

“... identificar a existência de atividades da biblioteca integradas com as atividades pedagógicas" (BARBOZA, 1991, p. 385).

"Analisar a inclusão das bibliotecas nos planos de educação do estado de Pernambuco e nos programas das escolas públicas de primeiro e segundo graus; analisar a utilização das bibliotecas escolares pelas comunidades usuárias; verificar a adequação do acervo e dos serviços frente às necessidades dos alunos e professores" (BARROS, 1998, p.12).

Um dos diagnósticos (ABREU, 2004) focalizou especificamente a situação dos acervos. Dois estudos (MACIEL FILHO, 2001 e CRUZ, 1979) compararam seus resultados com parâmetros internacionais (UNESCO e IFLA), colocando em evidência as desvantagens das bibliotecas brasileiras. Finalmente, um diagnóstico foi realizado com o objetivo explícito de “... apresentar proposições iniciais de diretrizes e padrões para bibliotecas escolares brasileiras, a fim de melhorar o desenvolvimento e a eficiência dessas bibliotecas" (MAYRINK, 1991, p. 14).

Todos os autores mostraram conhecer de antemão a situação das bibliotecas, caracterizando-a como:

“insatisfatória” (MADUREIRA, 1985, p. 70), “precária” (QUEIROZ, 1985, p. 8; MARTINS, 1983, p. 68; MADUREIRA, 1985, p. 70), 
"deficiente" (MACIEL FILHO, 2001, p. 16),

"caótica” (CRUZ, 1979, p. 849; DUARTE, 1998, p. 103),

"grave e alarmante" (NASCIMENTO, 2007, p. 2),

“calamitosa” (PERUCCHI, 1999, p. 82) e

"lastimável” (MARTINS, 1983, p. 106).

Esses autores acreditavam que os resultados obtidos poderiam subsidiar propostas, sugestões e planos para auxiliarem na solução dos problemas identificados. Os trechos abaixo mostram que, na perspectiva de alguns autores, os diagnósticos constituíam o germe para a realização de ações que beneficiassem as bibliotecas da região. Nesse sentido, os diagnósticos pretendiam:

“... sugerir algumas medidas visando uma mudança da situação atual" (CRUZ, 1979, p. 842).

“... [servir] de subsídio para um planejamento que poderá ser um instrumento de fortalecimento para o nosso sistema de biblioteca escolar" (CARVALHO, 1984, p. 33).

“... propor subsídios que permitam a melhoria das condições de funcionamento das bibliotecas escolares, visando, a sua integração, de forma objetiva, no processo de ensino-aprendizagem" (MADUREIRA, 1985, p. 22).

“... verificar a situação real das bibliotecas escolares... para posterior elaboração de um plano de ação que atenda aos interesses da população escolar usuária desse serviço" (CUARTAS, 1987, p. 9).

“... apresentar propostas para a melhoria da situação biblioteconômica no contexto educacional” (DUARTE, 1998, p. 83).

“... apresentar uma visão realista das bibliotecas escolares e públicas que possa subsidiar futuras políticas educacionais nos municípios estudados..." (MACIEL FILHO, 2001, p. 295).

“... que os resultados desta pesquisa possam ser utilizados como um cenário para o desenvolvimento e implementação de novas políticas públicas de incentivo à leitura e implantação de bibliotecas em todas as escolas da Rede de Educação" (MARTINS, 2011).

Outros diagnósticos anteviam soluções e mencionavam a criação de programas ou sistemas de bibliotecas, demonstrando o desejo de solucionar os problemas de forma coletiva e antecipando uma ação que dependia de forte atuação política. Os trechos abaixo revelam esta vontade:

"É preciso adotar um programa a nível nacional visando dotar cada escola de uma biblioteca dinâmica e atualizada" (CRUZ, 1979, p. 849).

“... os resultados desta pesquisa poderão servir de argumento [...] para que se obtenha, junto aos órgãos de planejamento educacional de Santa Catarina, a implementação de um sistema de bibliotecas escolares" (ACB, 1981, p. 39).

“... servir de apoio a qualquer implantação e desenvolvimento de um sistema de bibliotecas escolares a nível estadual ou mesmo nacional" (MARTINS, 1983, p. 68).

“... visando à apresentação de subsídios para um futuro planejamento de um Sistema de Biblioteca Escolar” (CARVALHO, 1984, p. 49).

Bibl. Esc. em R., Ribeirão Preto, v. 1, n. 1, p. 1-29, 2012. 
Os diagnósticos revelam certa indignação, como exemplificado no trabalho de Cruz (1979, p. 849): "Quando se fala tanto na necessidade de melhorar o padrão de ensino no Brasil, não se pode mais admitir essa situação caótica”. Deixam transparecer um tom de denúncia, claramente explicitado por Nascimento (2007, p. 1) que pretendia diagnosticar e denunciar a real situação das bibliotecas das escolas de ensino fundamental da Rede Estadual de Ensino do Município de Ribeirão Preto - SP. Enfim, percebe-se no discurso dos autores uma crença genuína de que a precariedade das bibliotecas escolares estaria interferindo negativamente na qualidade da educação e que o desvelamento da situação, por meio desses estudos, constituiria um alerta para os responsáveis.

\subsection{Metodologia e instrumentos de coleta de dados utilizados nos diagnósticos}

Todos os diagnósticos foram realizados por meio de pesquisa de campo, tendo sido a coleta de dados feita principalmente por meio de questionário. Outros instrumentos utilizados foram entrevista e observação (QUAD. 2).

QUADRO 2 - Instrumentos de coleta de dados utilizados nos diagnósticos

\begin{tabular}{|c|c|c|c|c|c|}
\hline Diagnósticos & Ano & Questionário & Entrevista & Observação & Respondentes \\
\hline CRUZ & 1979 & X & $X$ & & Não menciona. \\
\hline $\mathrm{ACB}$ & 1981 & $\mathrm{X}$ & $\mathrm{X}$ & $\mathrm{X}$ & $\begin{array}{l}\text { Alunos, professores e diretores } \\
\text { e/ou bibliotecários. }\end{array}$ \\
\hline MARTINS & 1983 & $\mathrm{X}$ & & $\mathrm{X}$ & $\begin{array}{l}\text { Funcionários (bibliotecário ou } \\
\text { responsável pela biblioteca). }\end{array}$ \\
\hline CARVALHO & 1984 & $\mathrm{X}$ & $\mathrm{X}$ & & $\begin{array}{l}\text { Entrevista com os diretores das } \\
\text { escolas. Questionário respondido } \\
\text { por: secretárias, bibliotecários ou } \\
\text { auxiliares de biblioteca e } \\
\text { diretores. }\end{array}$ \\
\hline MADUREIRA & 1885 & $\mathrm{X}$ & $\mathrm{X}$ & $\mathrm{X}$ & $\begin{array}{l}\text { Não menciona quem respondeu } \\
\text { ao questionário. Entrevista com } \\
\text { os responsáveis pelas bibliotecas. }\end{array}$ \\
\hline QUEIRÓZ & 1985 & & $\mathrm{X}$ & & $\begin{array}{l}\text { Diretor, professor, responsáveis } \\
\text { pelas bibliotecas. }\end{array}$ \\
\hline CUARTAS & 1987 & & $\mathrm{X}$ & & $\begin{array}{l}\text { Professores atuantes nas } \\
\text { bibliotecas. }\end{array}$ \\
\hline MAYRINK * & 1991 & $\mathrm{X}$ & $\mathrm{X}$ & & $\begin{array}{l}\text { Bibliotecários ou responsáveis } \\
\text { pelas bibliotecas e diretores. }\end{array}$ \\
\hline BARBOZA * & 1991 & $\mathrm{X}$ & & & $\begin{array}{l}\text { Diretores das escolas e } \\
\text { responsáveis pela biblioteca. }\end{array}$ \\
\hline BARROS & 1998 & $\mathrm{X}$ & & & $\begin{array}{l}\text { Diretores das escolas, } \\
\text { responsáveis pela biblioteca e } \\
\text { alunos. }\end{array}$ \\
\hline DUARTE & 1998 & $\mathrm{X}$ & $\mathrm{X}$ & $\mathrm{X}$ & $\begin{array}{l}\text { Dirigentes e responsáveis pelas } \\
\text { bibliotecas. }\end{array}$ \\
\hline MARTUCCI & 1999 & $\mathrm{X}$ & & & Responsáveis pelas bibliotecas. \\
\hline PERUCCHI & 1999 & & $\mathrm{X}$ & & $\begin{array}{l}\text { Diretores das escolas e } \\
\text { responsáveis pelas bibliotecas. }\end{array}$ \\
\hline
\end{tabular}




\begin{tabular}{|c|c|c|c|c|}
\hline MACIEL FILHO & 2001 & $\mathrm{X}$ & & Não menciona. \\
\hline ABREU & 2002 & $X$ & & Não menciona. \\
\hline ABREU & 2004 & $X$ & & Responsáveis pelas bibliotecas. \\
\hline NASCIMENTO & 2007 & $X$ & $\mathrm{X}$ & Responsáveis pelas bibliotecas. \\
\hline MARTINS & 2011 & $\mathrm{X}$ & & Não menciona. \\
\hline
\end{tabular}

Apenas sete, dos quinze diagnósticos que utilizaram questionário, incluíram-no como anexo e apenas três dos cinco que utilizaram observação anexaram o respectivo roteiro. Esses instrumentos estão mais presentes nas teses e dissertações. Oito, dos dezoito diagnósticos, não informaram o período de coleta de dados e quatro não explicitaram quem foi o respondente. Em um deles (CUARTAS, 1987, p. 10) foi mencionado como respondente o "professor bibliotecário", quando, na verdade, apenas 9,00\% dos respondentes possuíam graduação em biblioteconomia, ou seja, eram bibliotecários. Em muitos casos, as informações sobre metodologia e instrumentos de coleta de dados foram pouco acuradas, observando-se imprecisão na descrição do universo de pesquisa, na definição da amostra e na categorização dos respondentes.

A apresentação dos resultados foi feita, em geral, por percentagens ou simplesmente apresentando os números absolutos, no caso de dados quantitativos, ou de forma descritiva, no caso de dados qualitativos. A análise era realizada quase sempre confrontando-se os dados com a revisão de literatura. Houve exceção no trabalho de Martins (1983, p. 80) que, para analisar comparativamente informações de escolas públicas e de particulares utilizou o Teste U de Sidney Siegel (1956) $)^{5}$ o que lhe permitiu verificar que as primeiras estavam em melhor situação. Entretanto, a autora não explicitou na metodologia como utilizou o instrumento.

\subsection{O referencial teórico dos diagnósticos}

Neste aspecto, foram analisados os conceitos de biblioteca escolar que forneceram o embasamento e justificativa para os diagnósticos. Foi possível visualizar três conceitos mais presentes: biblioteca e escola, biblioteca e leitura, biblioteca e aprendizagem, sendo que sua apresentação variou em extensão e em profundidade, tendo em vista, entre outros fatores, a diversidade de documentos em que os diagnósticos foram publicados, desde teses de doutorado até trabalhos apresentados em eventos. Desta forma, todos eles deixaram entrever,

\footnotetext{
${ }^{5}$ SIEGEL, Sidney. Nonparametric statistics; for the behavioral sciences. New York, NY: McGraw Hill Book, 1956. (MARTINS, 1983, p. 117).
}

Bibl. Esc. em R., Ribeirão Preto, v. 1, n. 1, p. 1-29, 2012. 
ainda que implicitamente em alguns casos, a concepção de biblioteca escolar em que seus autores se basearam e na qual acreditavam.

\subsubsection{Biblioteca e escola}

A primeira noção que emergiu da análise, e que está presente em nove dos dezoito diagnósticos, é a de que a biblioteca escolar seria elemento essencial da escola. Usando expressões como:

"instrumento importante para o desenvolvimento satisfatório das atividades de ensino-aprendizagem" (CRUZ, 1979, p. 841);

"elemento de apoio, parte integrante do programa educacional" (ACB, 1981, p. 41);

"parte integrante da estrutura escolar" (MARTINS, 1983, p. 12);

"fator preponderante no processo educativo" (MADUREIRA, 1985, p. 20);

"órgão de apoio a todo e quaisquer programas educativos ... um instrumento do processo de ensino-aprendizagem" (DUARTE, 1998, p. 83-84) e

"força propulsora do processo educacional" (PERUCCHI, 1999, p. 81).

Os autores reforçaram sua crença de que a presença da biblioteca na escola seria óbvia. Queiroz (1985, p. 48-49) demonstrou visão crítica sobre essa obviedade e relacionou a biblioteca não simplesmente à escola e ao ensino, mas à educação de boa qualidade. Relativizou a discussão, lembrando que não havia estudos suficientes que demonstrassem o impacto que a utilização dos recursos da biblioteca tinha na formação intelectual dos estudantes. Carvalho (1984, p. 29) também aprofundou a relação biblioteca-ensino, criticando os educadores que não se preocupam com a "necessidade de ensinar ao educando a processar a informação, a transformá-la e a utilizá-la num outro contexto", mostrando que a biblioteca só adquire centralidade na escola se os professores repensarem suas práticas pedagógicas, abandonando atitudes acomodadas, ou seja, passando a trabalhar com estratégias centradas no aluno.

Os diagnósticos se preocupavam em enfatizar que:

“escola e biblioteca são inseparáveis" (CARVALHO, 1984, p. 34).

"Ensino e biblioteca são instrumentos complementares" (DUARTE, 1998, p. $84)$.

“... a biblioteca deve ser organizada para integrar-se com a sala de aula no desenvolvimento do currículo escolar" (PERUCCHI, 1999, p. 81) e

“... deve estar plenamente integrada ao processo pedagógico" (MARTINS, 2011).

A relação com a aprendizagem foi reforçada pela utilização de expressões que 
definiam a biblioteca escolar como:

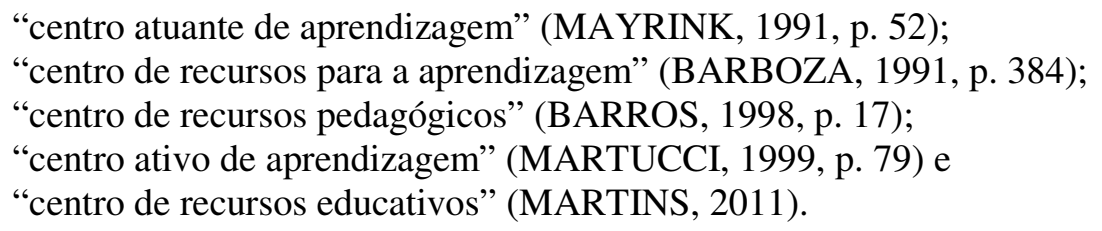

Os discursos encorajavam e exortavam a proximidade sem, entretanto, aprofundar-se nas dificuldades que essa relação implica. No de Maciel Filho (2001) este tema foi colocado na forma de questões:

"Será que é possível desenvolver os sistemas de ensino e pesquisa sem o apoio deste banco central de informações? Como é possível atender às necessidades de informação provenientes das mudanças constantes e crescentes desta nova sociedade?"

mostrando, portanto, que o autor também acreditava na biblioteca escolar como parte integrante da escola.

\subsubsection{Biblioteca e leitura}

A responsabilidade tradicional da biblioteca escolar com a leitura apareceu em dez diagnósticos. Segundo alguns deles (MARTINS, 1983; CARVALHO, 1984; MADUREIRA, 1985; MAYRINK, 1991; BARBOZA, 1991; BARROS, 1998; MARTUCCI, 1999), a biblioteca deveria incentivar, estimular, fomentar ou despertar a prática, o hábito e o gosto pela leitura, desempenhando papel ativo na formação do leitor. A leitura, e por extensão a biblioteca, era vista como capaz de contribuir para a formação de indivíduos críticos (MARTINS, 1983; CARVALHO, 1984; BARBOZA, 1991; BARROS, 1998; DUARTE, 1998; MARTUCCI, 1999; PERUCCHI, 1999). Essa crença na capacidade da biblioteca ficou clara nas palavras de Duarte $(1998$, p. 84) que considerou a biblioteca fundamental "na formação da personalidade da criança”, principalmente se esta não tem contato com a leitura em casa, idéia compartilhada por Perucchi (1999, p. 86) e por Carvalho (1984, p. 34) que também demonstrou acreditar no poder da leitura, no sentido de que ela pode levar o indivíduo "... a despertar para novos conhecimentos, a tornar-se um autodidata preparado para desenvolver todo o seu potencial". Ainda conforme Carvalho (1984, p. 41), a biblioteca escolar, por meio da leitura, "deve contribuir não somente para o desenvolvimento intelectual, mas também, para o desenvolvimento social do educando, ensinando-o a conviver com as pessoas, a respeitá-las e zelar pelo bem coletivo”, com o que concordou Perucchi (1999, p. 
86), que considerou que os bons livros "ajudam a dominar os problemas éticos, morais e sócio-políticos da vida”.

\subsubsection{Biblioteca e aprendizagem}

O diagnóstico de Abreu (2002, p. 2) introduziu a relação da biblioteca com a aprendizagem construtivista: a biblioteca seria o espaço que possibilitaria a utilização de metodologias que podem levar o estudante a produzir conhecimento. Outra relação que apareceu em diagnósticos mais recentes (BARBOZA, 1991; MARTUCCI, 1999; ABREU, 2002; MACIEL FILHO, 2001; NASCIMENTO, 2007) foi a da biblioteca escolar com a aprendizagem permanente. Esses autores acreditavam que a biblioteca poderia contribuir para preparar os alunos para aprenderem ao longo da vida, conforme demandado pela sociedade da informação ou do conhecimento.

A análise dos referenciais teóricos dos diagnósticos revelou uma grande contradição: a maioria dos autores insistia numa concepção de biblioteca ideal que contrastava radicalmente com a realidade encontrada. Pode-se dizer que a realidade inviabilizava as grandes funções pensadas para a biblioteca e precisava ser, na opinião dos autores, urgentemente modificada, a fim de garantir a educação de qualidade.

\subsection{Os dados obtidos pelos diagnósticos}

Considerando-se a extensa gama de dados apresentados nos resultados dos diagnósticos, serão comentados aqui apenas aqueles que estiveram presentes na maioria dos documentos, a saber: espaço físico, acervo, pessoal e serviços/atividades.

\subsubsection{Espaço físico}

Propondo-se a conhecer as condições de funcionamento das bibliotecas, dezesseis diagnósticos coletaram informações sobre o espaço físico, em diferentes níveis de aprofundamento. Treze verificaram especificamente a existência de espaço próprio para a biblioteca, apresentando dados quantitativos (TAB. 1). 
TABELA 1 - Existência de espaço próprio para funcionamento

\begin{tabular}{lll}
\hline \multicolumn{1}{c}{ Diagnóstico } & Ano & Bibliotecas que funcionavam em espaço próprio $(\%)$ \\
\hline BARBOZA & 1991 & 100,00 \\
ABREU & 2002 & 96,73 \\
ACB & 1981 & 95,50 \\
MARTUCCI & 1999 & 88,89 \\
CUARTAS & 1987 & 88,00 \\
CARVALHO & 1984 & 79,77 \\
PERUCCHI & 1999 & 75,00 \\
QUEIRÓZ & 1985 & 68,18 \\
CRUZ & 1979 & 60,00 \\
MARTINS & 2011 & 59,00 \\
MAYRINK & 1991 & 50,00 (públicas) \\
NASCIMENTO & 2007 & 33,33 (particulares) \\
MADUREIRA & 1985 & 27,05 \\
\hline
\end{tabular}

Percebe-se grande variação nos percentuais apresentados, que vão de 100,00\% (em escolas particulares de Recife) a 27,05\% (em escolas públicas estaduais do Paraná). Em onze dos treze diagnósticos que apresentaram este dado, mais da metade das bibliotecas contavam com espaço próprio, indicando que havia nas escolas uma pretensão de que ela fosse um lugar físico. Entretanto, alguns diagnósticos não esclarecem se este é um espaço exclusivo, sendo possível que ele seja compartilhado com outros setores da escola, problema que persiste desde o primeiro (1979) até o último (2011) diagnóstico, como pode ser comprovado pelos seguintes trechos:

"Em uma escola a sala da biblioteca funciona juntamente com a da administração e em outra com a sala de arte" (CRUZ, 1979, p. 843);

"A sala funciona como Orientação, Farmácia, Secretaria do Mobral e Biblioteca" (MADUREIRA, 1985, p.55);

"... compartem a sala com outros setores da escola como almoxarifado, merenda, etc." (CUARTAS, 1987, p.11);

"... a biblioteca funciona com o xérox e a sala dos professores" (PERUCCHI, 1999, p. 88);

“... em $11,11 \%$, a sala da biblioteca é compartilhada com outras atividades: ... sala de inspetor de alunos e com a sala de vídeo" (MARTUCCI, 1999, p. $88)$.

“... em $62,50 \%$ das escolas, tais espaços [bibliotecas] constituíam[-se] de salas adaptadas e improvisadas... quase sempre salas de aulas, laboratórios e até mesmo banheiros desativados e adaptados..." (NASCIMENTO, 2007, p. 9);

“... 34,00\% das bibliotecas dividem [...] espaço com outros setores como secretaria, sala de descanso dos professores, coordenação ou sala de permanência" (MARTINS, 2011, p. 10). 
Com relação à área ocupada pelas bibliotecas, apenas Martucci (1999) e Abreu, (2002), que utilizaram o mesmo instrumento para a coleta dos dados, apresentaram resultados passíveis de comparação (TAB. 2).

TABELA 2 - Área ocupada pelas bibliotecas

\begin{tabular}{|c|c|c|c|c|}
\hline \multirow{2}{*}{ Diagnóstico } & \multicolumn{4}{|c|}{ Área ocupada pela biblioteca $(\%)$} \\
\hline & Até $50 \mathrm{~m}^{2}$ & $\begin{array}{c}\text { De } 50 \mathrm{a} \\
70 \mathrm{~m}^{2}\end{array}$ & De 70 a $100 \mathrm{~m}^{2}$ & Mais de $100 \mathrm{~m}^{2}$ \\
\hline MARTUCCI & 55,55 & 16,67 & 27,78 & $\begin{array}{ll}----- \\
\end{array}$ \\
\hline ABREU & 48,36 & 24,18 & 18,30 & 9,16 \\
\hline
\end{tabular}

Abreu (2002, p. 6) verificou que, das 153 bibliotecas estudadas, apenas doze tinham espaço maior que $100 \mathrm{~m}^{2}$, dado que não foi apresentado por Martucci (1999). Maciel Filho (2001, p. 6) constatou uma área média de $68,55 \mathrm{~m}^{2}$ por biblioteca, Madureira (1985, p. 36) observou que a maioria das bibliotecas por ela pesquisadas tinha de 30 a $60 \mathrm{~m}^{2}$ e o diagnóstico da $\operatorname{ACB}\left(1981\right.$, p. 52) de 41 a $60 \mathrm{~m}^{2}$. Os dados sobre o tamanho das bibliotecas, embora coletados de formas diferentes pelos diagnósticos, apontam para um espaço exíguo (que corresponde aproximadamente ao tamanho de uma sala de aula padrão ${ }^{6}$ ) o que, sem dúvida, poderá influenciar nos serviços prestados.

Outros dados sobre espaço físico foram apresentados de forma esparsa, como por exemplo: localização da biblioteca na escola, existência de espaços para atividades específicas, mobiliário, equipamentos, iluminação, decoração, ventilação, servindo para confirmar as deficiências geralmente encontradas.

\subsubsection{Acervo}

Todos os dezoito diagnósticos abordaram, com maior ou menor profundidade, questões relativas ao acervo das bibliotecas. Essas questões incluíram: quantidade e tipo de material, organização do acervo, responsável pela seleção, forma de aquisição, critérios de seleção, grau de atualização, adequação, avaliação e estado de conservação do acervo.

A disparidade das técnicas de coleta dos dados quantitativos sobre o tamanho dos acervos e a maneira como foram apresentados impede a comparação ampla dos resultados dos

\footnotetext{
${ }^{6}$ Normas para tamanho de sala de aula foram encontradas apenas no Paraná. Nesse Estado, o tamanho padrão de uma sala de aula é de $1,2 \mathrm{~m}^{2}$ por aluno, além de mais $12 \mathrm{~m}^{2}$ para o professor, ou seja, mais ou menos $48 \mathrm{~m}^{2}$ para uma turma de 30 alunos.
} 
diagnósticos que apresentaram esse tipo de informação. Levando-se em consideração este ponto, é possível fazer a síntese de dois aspectos: média de livros por biblioteca (TAB. 3) e número de livros por aluno.

TABELA 3 - Média de livros por biblioteca

\begin{tabular}{lll}
\hline Diagnóstico & Ano & Média de livros por biblioteca \\
\hline MARTUCCI & 1999 & 4039 \\
MAYRINK & 1991 & 3760 (escolas públicas) - 3146 (escolas particulares) \\
ABREU & 2002 & 2961 \\
ACB & 1981 & 2152 \\
MACIEL FILHO & 2001 & 1711,71 \\
MADUREIRA & 1985 & 1486 \\
\hline
\end{tabular}

A média de livros por biblioteca variou entre 1486 livros (nas escolas públicas estaduais do Paraná) a 4039 (nas escolas públicas de São Carlos, SP).

Quatro diagnósticos (CARVALHO, 1984, QUEIROZ, 1985, ABREU, 2004 e MARTINS, 2011) coletaram os dados sobre a quantidade de livros por faixa. Devido à disparidade na definição das faixas não é possível agrupar os dados, apresentando-se apenas as faixas onde cada diagnóstico identificou a maior concentração (TAB. 4).

TABELA 4 - Quantidade de livros por faixas

\begin{tabular}{lll}
\hline Diagnóstico & Ano & Faixas de maior concentração \\
\hline CARVALHO & 1984 & $\begin{array}{l}\text { De } 2001 \text { a } 3000 \text { itens } \\
\text { Até } 299 \text { livros e }\end{array}$ \\
QUEIROZ & 1985 & de 2001 a 4000 livros \\
ABREU & 2004 & De 2001 a 9000 livros \\
MARTINS & 2011 & Até 500 exemplares \\
\hline
\end{tabular}

O número de livros por aluno, dado coletado por quatro diagnósticos, é mostrado no TAB. 5.

TABELA 5 - Média de livros por aluno

\begin{tabular}{lll}
\hline Diagnóstico & Ano & Média de livros por aluno \\
\hline MAYRINK & 1991 & 4,2 (escolas privadas) \\
& & 3,3 (escolas públicas) \\
ABREU & 2004 & 3,56 \\
CRUZ & 1979 & 2,93 \\
MADUREIRA & 1985 & 2,26 \\
\hline
\end{tabular}


Foi possível observar três diferentes tipos de análise feita pelos autores, com relação aos dados quantitativos dos acervos. Cruz (1979), Martucci (1999) e Abreu (2002) apenas apresentaram os dados levantados. Madureira (1985), Queiroz (1985) e Carvalho (1984) demonstraram simplesmente um "sentimento" de que o acervo era insuficiente, exemplificado pelas seguintes falas:

"Quando existe acervo, este, na maioria das vezes não é adequado aos usuários, nem na quantidade e muito menos na qualidade" (CARVALHO, 1984, p. 118),

"As bibliotecas escolares possuem um acervo muito aquém do mínimo essencial para o atendimento satisfatório..." (MADUREIRA, 1985, p. 57),

“... essas coleções apresentam um estado generalizado de pobreza, no tocante ao seu tamanho...” (QUEIROZ, 1985, p. 79).

Apenas Maciel Filho (2001) e Mayrink (1991) utilizaram parâmetros para análise. Maciel Filho (2001, p. 11) constatou que a quantidade de livros nas bibliotecas que pesquisou estava "muito aquém" dos parâmetros da UNESCO, e Mayrink (1991, p. 122) constatou que a proporção aluno/livro encontrada em sua pesquisa estava "distante" da média recomendada pela IFLA.

Os dados sobre os tipos de materiais constantes dos acervos também apresentaram grande disparidade no que diz respeito ao modo como foram coletados. Realizando levantamento quantitativo ou apenas observando os acervos, os diagnósticos que coletaram esses dados chegaram a conclusões semelhantes, assim sintetizadas:

- o material mais comum dos acervos é o livro;

- há presença significativa de livros didáticos;

- há pouca presença de materiais não bibliográficos ou materiais especiais.

Outros dados coletados sobre as coleções dizem respeito à: principal responsável pela seleção, critérios de seleção, forma de aquisição predominante, grau de atualização, grau de adequação, prática de avaliação do acervo e estado de conservação. Coletados por meio de observação ou de opinião dos usuários, esses dados mostram-se fragmentados e não revelam padrões, a não ser no caso da forma de aquisição predominante, que nos seis diagnósticos em que foi verificada, mostrou ser a doação.

Dados sobre a organização do acervo (registro, catalogação e classificação) foram

\footnotetext{
7 Tendo utilizado o mesmo questionário que Martucci (1999), Abreu (2002) pode comparar seus dados com os desse diagnóstico.
} 
apresentados por cinco diagnósticos, podendo ser observados na TAB. 6.

TABELA 6 - Organização do acervo

\begin{tabular}{lcccc}
\hline Diagnóstico & Ano & \multicolumn{2}{c}{ Organização do acervo } \\
\cline { 3 - 5 } & & $\begin{array}{l}\text { Têm acervo } \\
\text { registrado (\%) }\end{array}$ & $\begin{array}{l}\text { Têm acervo } \\
\text { catalogado (\%) }\end{array}$ & $\begin{array}{l}\text { Têm acervo } \\
\text { classificado (\%) }\end{array}$ \\
\hline CRUZ & 1979 & 56,66 & 26,00 & 30,00 \\
CARVALHO & 1984 & 47,89 & 22,54 & 23,94 \\
MADUREIRA & 1985 & 26,25 & 8,55 & 7,96 \\
QUEIROZ & 1985 & ---- & 13,63 & 22,72 \\
ABREU & 2002 & 96,66 & 89,16 & 63,33 \\
\hline
\end{tabular}

Sabe-se que dados quantitativos sobre acervos são difíceis de serem coletados devido a diversos fatores. Em primeiro lugar, grande parte das bibliotecas sequer tem seus acervos registrados. Aquelas que o fazem não utilizam sistemas de registro que permitam segmentar a coleção por tipo de material, ou distinguir a diferença entre número de títulos, volumes e exemplares. Além disso, a presença maciça de livros didáticos em muitas bibliotecas mascara o tamanho do acervo. Assim, os dados apresentados pelos diagnósticos são limitados por esses fatores e devem ser vistos de forma abrangente e não como um retrato fiel dos acervos.

\subsubsection{Pessoal}

Dos dezoito diagnósticos, apenas Abreu $(2004)^{8}$ e Perucchi (1999) não coletaram dados sobre a existência de bibliotecários graduados em Biblioteconomia. Martucci (1999, p. 86), embora o tenha feito, agregou os dados dos bibliotecários aos dos funcionários de apoio, impedindo de se verificar a quantidade de bibliotecários graduados. Quinze diagnósticos apresentaram essa porcentagem (TAB. 7). A maior foi encontrada por Barboza (1991, p. 396) que verificou que 35,00\% das bibliotecas de escolas particulares de Recife tinham bibliotecários, e a mais baixa por Mayrink (1991, p. 100-120), Nascimento (2007, p. 7) e Martins (2011, p. 11) que constataram não haver bibliotecário nas bibliotecas que estudaram.

\footnotetext{
${ }^{8}$ Este diagnóstico coletou dados apenas sobre os acervos.
} 
TABELA 7 - Dados relativos à existência de bibliotecário

\begin{tabular}{|c|c|c|}
\hline Diagnóstico & Ano & Tem bibliotecário (\%) \\
\hline \multirow{2}{*}{ MARTINS } & \multirow{2}{*}{1983} & 62,00 (escolas públicas) \\
\hline & & 0,00 (escolas particulares) \\
\hline BARBOZA & 1991 & 35,00 \\
\hline $\mathrm{ACB}$ & 1981 & 21,80 \\
\hline DUARTE & 1998 & 17,07 \\
\hline CARVALHO & 1984 & 15,48 \\
\hline QUEIRÓZ & 1985 & 13,63 \\
\hline CRUZ & 1979 & $10,00^{*}$ \\
\hline CUARTAS & 1987 & 9,00 \\
\hline BARROS & 1998 & 6,70 \\
\hline ABREU & 2002 & 3,78 \\
\hline MACIEL FILHO & 2001 & Menos de 3,00 \\
\hline MADUREIRA & 1985 & $2,10 * *$ \\
\hline MARTINS & 2011 & 0,00 \\
\hline MAYRINK & 1991 & 0,00 \\
\hline NASCIMENTO & 2007 & 0,00 \\
\hline
\end{tabular}

* Professores graduados em biblioteconomia, mas que não ocupam o cargo.

** Dado relativo a apenas 291 bibliotecas com responsável, das 682 estudadas.

O nível de formação dos funcionários foi registrado por oito diagnósticos e as porcentagens apresentam grande variação. Na TAB. 8 é possível visualizar-se as porcentagens referentes a funcionários com formação superior.

TABELA 8 - Porcentagem de funcionários com formação superior

\begin{tabular}{lll}
\hline Diagnóstico & Ano & Funcionários com formação superior (\%) \\
\hline BARROS & 1998 & 90,00 (professores de ensino superior) \\
NASCIMENTO & 2007 & 62,50 \\
MARTUCCI & 1999 & 58,62 \\
ACB & 1981 & 50,00 \\
ABREU & 2002 & 38,60 \\
MADUREIRA & 1985 & 36,76 \\
BARBOZA & 1991 & 29,03 \\
QUEIROZ & 1985 & 25,00 \\
CARVALHO & 1984 & 12,00 (auxiliares) \\
\hline
\end{tabular}

Os dados sobre recursos humanos podem ser sintetizados nos seguintes aspectos:

- pequeno número de responsáveis com formação em biblioteconomia;

- presença constante do professor readaptado e 
- falta de treinamento da equipe.

Nascimento (2007, p.7) resume a questão: “A situação encontrada em relação aos recursos humanos foi de extrema gravidade, constituindo talvez o maior problema detectado na pesquisa”, secundada por Abreu (2002, p. 13), que concluiu que a análise dos dados revela “... a persistência de problemas, dos quais o mais evidente é o de pessoal”.

\subsubsection{Serviços e atividades}

A existência de serviços de consulta no local e/ou de empréstimo domiciliar foi verificada por catorze dos dezoito diagnósticos, sendo que oito desses apresentaram porcentagens das bibliotecas que os ofereciam, podendo ser comparadas na TAB. 9.

TABELA 9 - Oferecimento de serviço de empréstimo domiciliar e consulta no local

\begin{tabular}{lccc}
\hline \multicolumn{1}{c}{ Diagnóstico } & Ano & Empréstimo domiciliar (\%) & Consulta no local (\%) \\
\hline MAYRINK & 1991 & 100,00 (públicas) & 50,00 (públicas) \\
MARTUCCI & 1999 & 100,00 & 100,00 \\
NASCIMENTO & 2007 & 100,00 & ------------ \\
CUARTAS & 1987 & 96,00 & ------------ \\
ABREU & 2002 & 70,74 & 97,39 \\
QUEIRÓZ & 1985 & 68,19 & 22,72 \\
CARVALHO & 1984 & 66,19 & 94,36 \\
DUARTE & 1998 & 32,10 (públicas) & ------------ \\
\hline
\end{tabular}

Madureira (1985) e Barboza (1991) mencionaram que estes estavam entre os serviços mais oferecidos:

\footnotetext{
"Os serviços de consulta (386) e empréstimos (324) são os predominantes nas bibliotecas..." (MADUREIRA, 1985, p. 48).

“... os serviços que aparecem com maior destaque $(69,00 \%)$ referem-se à consulta, orientação bibliográfica, levantamento bibliográfico e empréstimo domiciliar" (BARBOZA, 1991, p. 394).
}

Três diagnósticos apresentaram dados de quem não oferecia o serviço de empréstimo, conforme observado nas afirmações a seguir:

"53,40\% das bibliotecas das escolas públicas não realizam empréstimos a domicílio para os alunos; nas escolas particulares isso ocorre com $37,50 \%$ delas" (ACB, 1981,p. 54).

"A maioria das bibliotecas, 66,00\% aproximadamente, não oferecem um serviço regular de empréstimo domiciliar..." (MARTINS, 1983, p. 98). 
“... a maioria das escolas (47 instituições) só permite o uso dos livros em consulta local ou sala de aula, limitando o empréstimo domiciliar" (MARTINS, 2011, p. 10).

Mais uma vez a diversidade na forma de coletar e apresentar os dados impede a visualização clara de padrões no que diz respeito a esses serviços, o mesmo ocorrendo com os treze diagnósticos que coletaram dados sobre outros serviços e atividades. Nesse caso, chama atenção a variedade de atividades encontradas: hora do conto, palestras, exposições, concursos literários, clube de leitura, comemoração de datas, feiras, visitas guiadas, orientação de usuários, treinamento de usuários, mural de notícias, levantamento bibliográfico, divulgação de novos materiais, banco do livro, dramatização, projeções, fantoches, apoio didático em sala de aula, empréstimo entre bibliotecas, concurso de redação, gincana, entre outras. Alguns desses dados foram apresentados na forma de percentagens e, em geral, as análises sobre serviços/atividades foram bastante superficiais tendo, alguns autores, buscado relacioná-los com outros fatores.

De acordo com Carvalho (1984, p. 103), "pelo fato de a maioria das bibliotecas não serem tecnicamente organizadas e de não existir uma preocupação maior nas escolas de incentivar o uso das mesmas" é compreensível a baixa percentagem de treinamento de usuários encontrada.

Abreu (2002, p. 13), que encontrou percentagem alta para consulta no local e empréstimo domiciliar e, considerando esses serviços como rotineiros, relacionou o fato com a prática de deslocamento do professor para a biblioteca:

... deslocado para a biblioteca o professor não se mostra capaz e/ou interessado em desempenhar o papel de administrador de acervos informacionais. Isso parece refletir diretamente nos serviços oferecidos: o mais comum são os serviços rotineiros, que não exigem planejamento ou ação proativa do funcionário, além de não demandarem integração com o corpo docente.

Martins (2011, p. 10), relacionou a deficiência dos serviços com a falta de pessoal qualificado, considerando que:

Aparentemente uma das dificuldades em se oferecer serviços variados e disponibilizar os materiais para empréstimo domiciliar reside na falta de profissionais para conduzir os trabalhos na biblioteca escolar.

Queiroz (1985, p. 94) faz uma constatação interessante quando descobre que:

Os dados [...] deixam claro que o fato de ter bibliotecário habilitado não altera a quantidade de serviços oferecidos pelas bibliotecas, no que concerne 
à diversificação desses serviços, pois, [...] as duas bibliotecas que tem bibliotecário desenvolvem apenas atividades como consulta local, empréstimo domiciliar e uma delas faz divulgação do acervo.

Esses exemplos ilustram o nível das análises, bem como apontam para a complexidade que precisa ser levada em consideração em futuros estudos.

\subsection{Conclusões dos diagnósticos}

Conforme dito anteriormente, os autores dos diagnósticos mostravam conhecer de antemão a situação precária das bibliotecas e, coerentemente, nas conclusões enfatizaram as deficiências encontradas, como ilustram os exemplos a seguir:

“... constatamos que as bibliotecas escolares estão desaparelhadas, sem acervo adequado e sem pessoal especializado" (MAYRINK, 1991, p. 180). "As bibliotecas escolares encontradas são demasiadamente simples, consistindo apenas germens de bibliotecas..." (MARTINS, 1983, p. 106).

“... apesar de uma parte expressiva das instituições pesquisadas afirmarem ter bibliotecas, as questões seguintes, referentes às instalações, acervos e serviços, demonstram que estes espaços estão pouco qualificados para serem considerados plenamente como bibliotecas escolares" (MARTINS, 2011, p. $11)$.

"Existem poucas bibliotecas escolares, e as existentes não satisfazem as necessidades de seus usuários" (PERUCCHI, 1999, p. 94).

"Ao se concluir o relatório [...] tem-se uma convicção assegurada pelos fatos: na área pesquisada a situação de bibliotecas escolares e públicas é merecedora de atenção em face às deficiências encontradas" (MACIEL FILHO, 2001, p. 16).

Alguns diagnósticos que colheram a opinião dos participantes concluíram que, pelo menos, existia um discurso propício às bibliotecas escolares. Nesta linha, Barboza (1991, p. 397) ressaltou em sua conclusão que "os colégios que oferecem ensino de $1^{\circ}$ e $2^{\circ}$ graus da Rede Privada da Cidade do Recife se encontram em condições favoráveis para o funcionamento de boas bibliotecas".

Barros (1998, p. 74) que, como Barboza (1991), estudou bibliotecas de Recife, concluiu que a biblioteca escolar:

... tem conseguido um espaço dentro da escola, diferente do que assumiram as primeiras bibliotecas escolares brasileiras. De museu com acervos sagrados e intocáveis, ela pode ser vista agora como alternativa de apoio aos programas escolares... O silêncio que se fazia sobre a biblioteca escolar, nesta experiência deu lugar ao reconhecimento de que ela precisa ser tirada do abandono e desprezo.

Entretanto, as duas autoras ressaltaram que isso constituía o discurso da importância 
da biblioteca escolar, e que a teoria deveria dar lugar à prática, para que as condições da biblioteca melhorassem e para que ela passasse a exercer sua ação educativa.

Abreu (2002, p. 13) também visualizou um ângulo favorável, neste caso, no fato de que grande porcentagem das bibliotecas que pesquisou contava com espaço físico de uso exclusivo, apressando-se, entretanto, a esclarecer que a análise mais aprofundada mostrava que, apesar disso, os problemas persistiam.

Confirmando a vontade dos autores de mudar a situação das bibliotecas escolares, que pode ser percebida em vários diagnósticos, Madureira (1985, p. 79) confessou na sua conclusão que, ao iniciar o trabalho, tinha a intenção de sugerir a implantação de uma rede de bibliotecas escolares, mas que ao final percebeu que tal pretensão seria uma utopia, dadas as condições das bibliotecas estudadas.

\subsubsection{Recomendações e sugestões feitas pelos diagnósticos}

Como Madureira (1985, p. 79), os autores dos diagnósticos não só conheciam a situação precária das bibliotecas, como já anteviam soluções para os problemas. Assim sendo, a maioria deles apresentou nas suas conclusões, em maior ou menor grau, recomendações e sugestões para resolvê-los. Houve sugestões genéricas, como as seguintes:

... é urgente que providências sejam tomadas, pelas autoridades competentes, mas isso só acontecerá no dia em que os interessados (educadores, bibliotecários e sociedade em geral) se mobilizarem na luta para que o Brasil tenha uma Sociedade da Informação para todos, que só será alcançada quando tiver uma educação de qualidade" (NASCIMENTO, 2007, p. 12). "Compete aos profissionais, aos órgãos de classe e às autoridades educacionais um esforço sistemático e rigoroso no sentido de propiciar as condições e oportunidades requeridas a nível de recursos humanos e financeiros, para que as bibliotecas escolares sejam realmente organismos vivos e atuantes no meio educacional, servindo melhor à comunidade (MARTINS, 1983, p. 114).

Em alguns casos, as recomendações se revelavam imprecisas, indeterminadas, indicando vagamente a vontade de mudança. Nesse sentido, os autores falavam sobre a necessidade de reconhecimento, conscientização, sensibilização dos diversos segmentos considerados responsáveis pela situação, demonstrando necessidade de convencimento sobre a importância da biblioteca. O trecho a seguir exemplifica o tom do discurso.

Prioritariamente, é necessário que os órgãos oficiais do Estado (Secretaria de Estado da Educação - SEED e Conselho Estadual de Educação - CEE) 
estejam conscientizados da importância e da necessidade da Biblioteca Escolar... (MADUREIRA, 1985, p. 78).

Segundo esta mesma autora, a sensibilização deveria atingir também professores, diretores, alunos e comunidade para “... conscientizá-los sobre as verdadeiras funções que a Biblioteca pode e deve cumprir no processo educacional" (MADUREIRA, 1985, p. 80).

Em alguns casos não ficava claro quem seria o responsável pelo trabalho de sensibilização, como mostrado nos trechos a seguir:

"Trabalho de conscientização e sensibilização junto aos diretores de colégios para canalizarem esforços e apoio na valorização dessas bibliotecas" (BARBOZA, 1991, p. 397);

"Sensibilizar os diretores escolares para o envolvimento de suas escolas com as atividades bibliotecárias" (CARVALHO, 1984, p.122).

\section{- Recomendações dirigidas a órgãos públicos}

Outras recomendações eram bem concretas, com diversos níveis de especificidade, e endereçadas a diferentes segmentos sociais, sendo a maioria delas dirigidas a órgãos públicos, como por exemplo, algumas de Carvalho (1984, p. 121), sugerindo que a Secretaria de Educação do Ceará se responsabilizasse pelo sistema de bibliotecas escolares do Estado, centralizando a "assistência às bibliotecas", criando um grupo de trabalho que seria responsável pelo planejamento e funcionamento do Sistema, estabelecendo orçamento para execução do planejamento anual, mantendo convênios com instituições voltadas para o mesmo objetivo e definindo bibliotecas em melhores condições (segundo o atual conceito de bibliotecas-polo) que funcionariam como apoio às outras.

Madureira (1985, p. 78), por sua vez, considerava que a situação precária das bibliotecas só se resolveria se os órgãos responsáveis pela educação no Estado do Paraná formulassem o que ela chamou de "legislações pertinentes". Sugeriu um Programa de Bibliotecas Escolares destinado a:

Implantar bibliotecas nas escolas que ainda não as possuam e fortalecer as já existentes; fornecer as condições mínimas de funcionamento relativas ao espaço físico, mobiliário adequado, acervo mínimo indispensável e recursos humanos qualificados ou treinados... (MADUREIRA, 1985, p. 80).

Nas suas recomendações, Barros (1998, p. 77) que em seu diagnóstico verificou melhoria na situação das bibliotecas escolares de Recife, relembrou propostas feitas pelo governo no passado, sugerindo a continuidade dos programas propostos nos planos de 
educação do Estado de Pernambuco que, segundo ela, ensejaram essas melhorias.

Duarte (1998, p. 103) sugeriu que o Conselho de Educação Estadual da Paraíba fiscalizasse e exigisse o bom desempenho das escolas (públicas e particulares) "principalmente os regulamentos referentes às bibliotecas" e Cruz $(1979$, p. 848) reclamou o repasse, pelos órgãos responsáveis pelas escolas estaduais, de verbas suficientes para instalação e manutenção de bibliotecas escolares e para a contratação de profissionais de biblioteconomia.

As recomendações de Queiroz (1985) foram categorizadas pelo tipo de problema encontrado e, em geral, não explicitavam a quem eram dirigidas. Algumas delas, entretanto, implicavam ação governamental, como as que diziam respeito a recursos financeiros, sugerindo a reformulação da legislação educacional, de forma a incluir e garantir recursos para o estabelecimento e a manutenção de bibliotecas escolares, propondo inclusive a descentralização da administração desses recursos, a fim de proporcionar maior flexibilidade para sua aplicação. Todavia, segundo a autora, o ideal seria que a legislação sobre biblioteca escolar "emanasse do órgão federal que coordena o ensino (o MEC), pois desse modo, teria uma abrangência maior, englobando todo território nacional", mas ela não descartava a possibilidade de que os órgãos estaduais e municipais também estabelecessem "leis concernentes ao assunto" (QUEIROZ, 1985, p. 112). Mayrink (1991, p. 173) sugeriu, com detalhes, um programa de integração entre bibliotecas públicas e escolares, acreditando que "uma vez definido bem o que é uma biblioteca escolar e uma biblioteca pública e quais seus objetivos e serviços, pode haver a aproximação dessas duas instituições, dividindo-se suas tarefas junto ao público estudantil e toda a comunidade", mas também deixa indefinido o foco dessas recomendações.

Dois diagnósticos lembraram a possibilidade de criação de bibliotecas que servissem de modelo para outras. Cruz (1979, p.849) sugeriu a implantação, em cada município do país, de bibliotecas modelo "dotadas com todos os recursos organizacionais e bibliográficos necessários", possibilitando que o padrão de biblioteca fosse progressivamente adotado em outras escolas. Queiroz (1985, p.115) também aventou esta solução, propondo a organização de uma biblioteca piloto, entre as que foram estudadas, com a posterior transmissão da experiência às outras bibliotecas escolares. 
- Recomendações dirigidas às escolas

Eram também esperadas mudanças no âmbito das escolas e sugestões foram dirigidas a diretores e professores para que houvesse "Maior e efetiva integração entre a biblioteca, o pessoal técnico-administrativo e o corpo docente da escola com a finalidade de conscientizar mais os professores sobre a importância da biblioteca" (CRUZ, 1979, p. 848). Madureira (1985, p. 79) também sugeriu a conscientização dos professores para que passassem a considerar a biblioteca como:

...suporte para o planejamento de desenvolvimento dos programas de ensino; como instrumento que contribui para melhoria da qualidade do ensino e, principalmente como apoio para a formação e o desenvolvimento do hábito de leitura e pesquisa de seus alunos.

Além dos professores, a conscientização deveria envolver diretores, alunos e a comunidade (MADUREIRA, 1985, p. 80). Aos professores sugeria-se incentivar o uso da biblioteca pelos alunos, considerando a grande influência que exercem sobre eles, especialmente na fase que vai da infância à adolescência (QUEIROZ, 1985, p. 113) e aos diretores recomendava-se "canalizar os esforços e apoio na valorização das bibliotecas escolares" (BARBOZA, 1991, p. 397).

Recomendações relativas à equipe das bibliotecas incluíram treinamento adequado, de forma a resolver o problema da carência de bibliotecários graduados. Queiroz (1985, p. 111), por exemplo, reiterava que:

Essa alternativa de treinar o professor-bibliotecário vem sendo recomendada por diversos autores, em diferentes países, e nos parece bastante apropriada para a realidade socioeconômica da região, visto que parecem longínquas as perspectivas de se alcançar as condições que permitam ter um bibliotecário qualificado em cada biblioteca escolar.

A mesma autora sugeria que os profissionais atuantes nas bibliotecas escolares relatassem e divulgassem suas práticas e experiências para "evitar a duplicação de esforços na busca de soluções de problemas idênticos" (QUEIROZ, 1985, p. 114).

- Recomendações dirigidas aos pais

Os pais também eram alvo das recomendações; tinham uma parcela de responsabilidade na melhoria das bibliotecas escolares e eram chamados a participar das 
mudanças consideradas necessárias. Duarte (1998, p. 103), que estudou bibliotecas de escolas públicas e particulares, por exemplo, afirmava que cabia aos pais:

... a responsabilidade de fiscalizar os serviços [educacionais] por eles contratados como forma de pressionar as empresas prestadoras de serviço, sob pena de amanhã não verem seus filhos inferiorizados diante das exigências do mercado globalizado.

Barboza (1991, p. 397) lembrava que um trabalho de sensibilização deveria ser feito com “... os pais que ao escolherem um colégio para os filhos sempre elegem critérios que devem ser atendidos - ambiente saudável, ensino de boa qualidade, professores qualificados, entre outros...". Deveriam, portanto, incluir outra exigência: a presença de bibliotecas bem equipadas.

\section{- Recomendações dirigidas à classe bibliotecária}

A classe bibliotecária foi também conclamada a assumir responsabilidade na questão. Duarte (1998, p. 103-104) recomendava "ao Conselho Regional de Biblioteconomia a fiscalização do exercício irregular da profissão, como forma de preservar o mercado de trabalho, coibindo o exercício ilegal da profissão por leigos que, por falta de qualificação, denigrem os conceitos de serviços bibliotecários" e que os profissionais, aliados aos órgãos de classe, promovessem “... uma campanha de conscientização junto às autoridades governamentais e empreendedores do ensino privado, da contribuição que o profissional de biblioteconomia poderá oferecer na formação dos alunos dos níveis fundamental e médio".

Barboza (1991, p. 397), por sua vez, acreditava na "ação conjunta" de diversos segmentos como: associações de bibliotecários, grupos de estudos em bibliotecas públicas e escolares, cursos de biblioteconomia e profissionais de educação, para a promoção de "cursos, seminários, reuniões visando à melhoria das bibliotecas escolares...”.

Os cursos de formação de bibliotecários também constituíram alvo de recomendações e foram criticados por Carvalho (1984, p.120), que reclamava "Maior reflexão sobre a formação de seus profissionais, dada a falta de articulação da universidade com a nossa realidade, além de não oferecer preparo para transformá-la". Os alunos, segundo ela, "ao passar pela universidade deveriam assumir atitude de criar e recriar as ideias tornando-se profissionais dinâmicos e atuantes na comunidade".

Queiroz (1985, 1985, p. 111) também fazia críticas à formação dos bibliotecários e Bibl. Esc. em R., Ribeirão Preto, v. 1, n. 1, p. 1-29, 2012. 
considerava que eles “... não têm tido uma atuação eficiente na biblioteca escolar e que a formação que ele vem recebendo nos cursos de biblioteconomia pode estar contribuindo para isso". Segundo a autora, os cursos de formação tinham a tarefa de despertar a consciência dos futuros profissionais para o problema social de dissociar o ensino da biblioteca.

No seu conjunto, as recomendações abrangiam múltiplos aspectos e sua análise mostra a complexidade da questão. Todos os envolvidos, direta ou indiretamente, foram chamados a ter uma atuação mais ativa no que dizia respeito à melhoria das condições das bibliotecas escolares, de forma a garantir um ensino de qualidade nas escolas.

A análise das recomendações revela o desejo dos autores por mudanças efetivas. Os programas sugeridos por Queiroz (1985, 1985, p. 109), por exemplo, deveriam, segundo a autora, ser “... fundamentados em experiências já testadas na prática e devidamente adaptados à realidade da Região da Grande Vitória, evitando-se planos de ação baseados em reflexões intuitivas". Maciel Filho (2001) recomendava "ações inovadoras", chamando atenção para o fato de que "Experiências governamentais passadas demonstram que programas voltados apenas para o acervo não modificaram a realidade das bibliotecas" e alertava para a necessidade de que as ações incluíssem também o espaço físico e a administração das bibliotecas.

\section{Perspectivas para novos diagnósticos}

Os diagnósticos analisados revelam a preocupação e, em alguns casos, a indignação da classe bibliotecária que os usou para denunciar a situação de bibliotecas escolares no Brasil. Mostram a crença da classe de que a biblioteca pode colaborar na educação, acreditam em uma função educativa para a biblioteca escolar. Mas não é qualquer biblioteca: tem que ser uma boa biblioteca.

No seu conjunto, esses trabalhos compõem um retrato parcial da biblioteca escolar no país, confirmando, na sua maioria, a situação precária dessas instituições e tornando mais visíveis os problemas existentes. Com o objetivo de conhecer a realidade de bibliotecas escolares de localidades específicas, as pesquisas se assemelham em suas abordagens críticas da realidade, além de sugerirem mudanças em prol de um sistema educacional mais eficiente.

Como já foi dito, as etapas metodológicas carecem de maiores informações e 
detalhamentos sobre os procedimentos científicos de pesquisa. A variedade de procedimentos de coleta e análise dos dados impossibilita inferências e conclusões gerais e abrangentes.

Mais do que apontar as deficiências de tais diagnósticos, entretanto, o presente trabalho pretendeu conhecer suas características para que futuros estudos nesse campo possam suplantar as deficiências e contribuir para o conhecimento mais efetivo da realidade não só local, mas também nacional das bibliotecas escolares do país.

Os diagnósticos estudaram conjuntos de bibliotecas de determinadas regiões, com a intenção clara de expor situações precárias e de sensibilizar para mudanças. São estudos que focalizam prioritariamente as deficiências, seguindo uma linha traçada por Waldeck Silva, no seu livro A miséria da biblioteca escolar, trabalho citado por quatro dos nove diagnósticos publicados depois de 1995, ano da primeira edição do referido livro.

Talvez fosse o momento de reverter o paradigma da miséria, e buscar expor aspectos positivos da biblioteca, revelando suas potencialidades como espaço de aprendizagem, e usando evidências científicas, mostrar como a biblioteca escolar pode ajudar crianças e jovens a aprender.

\section{Referências}

CAMPELLO, B. S. A função educativa da biblioteca escolar no Brasil: perspectivas para o seu aperfeiçoamento. In: ENCONTRO NACIONAL DE PESQUISA EM CIÊNCIA DA INFORMAÇÃO, 5., 2003, Belo Horizonte. Anais... Belo Horizonte: Escola de Ciência da Informação da UFMG, 2003. Disponível em:<http://www.ancib.org.br/media/dissertacao/ENAN054.pdf>. Acesso em 21 out. 2011.

FERREIRA, C. N. de C. Biblioteca pública é biblioteca escolar? R. bras. Bibliotecon. Doc., São Paulo, v. 11, n. 1/2, p. 9-16, jan./jun. 1978.

ORGANIZAÇÃO DOS ESTADOS AMERICANOS. Modelo flexível para um sistema nacional de bibliotecas escolares: Colômbia, Costa Rica, Peru, Venezuela. Brasília: [s.l.]: 1985. $280 \mathrm{p}$.

VIANNA, M. M.; CARVALHO, N. G. M.; SILVA, R. M. Entre luz e sombra...: uma revisão de literatura sobre biblioteca escolar. In: SEMINÁRIO BIBLIOTECA ESCOLAR ESPAÇO DE AÇÃO PEDAGÓGICA, 1., 1998, Belo Horizonte. Biblioteca escolar espaço de ação pedagógica. Belo Horizonte: Grupo de Estudos em Biblioteca Escolar: Escola de Ciência da Informação da UFMG: Associação dos Bibliotecários de Minas Gerais, 2004. Disponível em: <http://www.eci.ufmg.br/gebe/downloads/104.pdf>. Acesso em: 11 nov. 2007. 
ANEXO 1 Referências dos diagnósticos analisados (em ordem alfabética de autores) ${ }^{9}$

ABREU, Vera Lúcia Furst Gonçalves de et al. Diagnóstico das bibliotecas escolares da rede estadual de ensino de Belo Horizonte - MG. In: CONGRESSO BRASILEIRO DE BIBLIOTECONOMIA, DOCUMENTAÇÃO E CIÊNCIA DA INFORMAÇÃO, 20., 2002, Fortaleza. Anais... Fortaleza: Associação dos Bibliotecários do Ceará, 2002.

Diagnóstico das bibliotecas escolares da rede estadual de ensino de Belo Horizonte MG: a situação dos acervos. Encontros Bibli, Florianópolis, n. 17, p. 19-33, 1. sem. 2004. Disponível em:<http://www.periodicos.ufsc.br/index.php/eb/article/view/15182924.2004v9n17p19/5268>. Acesso em: 16 out. 2011.

ASSOCIAÇÃO CATARINENSE DE BIBLIOTECÁRIOS. Projeto de pesquisa e resultados preliminares sobre hábitos de leitura e bibliotecas escolares: um levantamento realizado nas escolas de $1^{\circ}$ e $2^{\circ}$ graus de Florianópolis. 2. ed. Florianópolis: ACB, 1981. 58 p.

BARBOZA, Josefa Pereira; SILVA, Corita Aguiar da; PIMENTEL, Edna Sitônio. Bibliotecas escolares da rede privada de ensino da cidade de Recife: análise da realidade. In: CONGRESSO BRASILEIRO DE BIBLIOTECONOMIA E DOCUMENTAÇÃO, 16., 1991, Salvador. Anais... Salvador: Associação Profissional dos Bibliotecários do Estado da Bahia, 1991. p. 384-399.

BARROS, Lucimar Martins de. A biblioteca escolar no planejamento educacional: análise em escolas públicas de $1^{\circ}$ e $2^{\circ}$ graus em Recife/PE. 1998. Dissertação (Mestrado em Biblioteconomia) - Curso de Biblioteconomia, UFPB, João Pessoa, 1998.

CARVALHO, Ana Maria Sá de. A biblioteca na escola. Fortaleza: SESI/SENAI, 1984. 150 p.

CRUZ, Vilma A. Gimenes da; WELFENS, Irma A. I. Lorenzo. Avaliação das bibliotecas escolares de $1^{\circ}$ grau da cidade de Londrina. In: CONGRESSO BRASILEIRO DE BIBLIOTECONOMIA E DOCUMENTAÇÃO, 10., 1979, Curitiba. Anais... Curitiba: Associação Bibliotecária do Paraná, 1979. v. 2, p. 841-851.

CUARTAS, Henriqueta Graciela D.; CORRÊA, Alba Maria Dourado. Diagnóstico da situação das bibliotecas pertencentes à $18^{\text {a }}$ Delegacia de Educação. Biblos, Rio Grande, v. 2, p. 9-15, 1987.

DUARTE, Emeide Nóbrega et al. Bibliotecas escolares no município de João Pessoa Paraíba: diagnóstico. Informação \& Sociedade, João Pessoa, v. 8, n. 1, p. 80-105, 1998. Disponível em: <http://dci2.ccsa.ufpb.br:8080/jspui/bitstream/123456789/326/1/v8_n1_1998_8.pdf>. Acesso em: 16 out. 2011.

\footnotetext{
${ }^{9}$ O diagnóstico referenciado a seguir, que coletou dados de bibliotecas de 29 escolas, não foi incluído, em razão de ter sido localizado após o término do presente relato:

LUZZI, Mariele. Diagnóstico das bibliotecas escolares municipais do Rio Grande do Sul: situação atual e perspectivas de dois municípios. Porto Alegre: Universidade Federal do Rio Grande do Sul: Faculdade de Biblioteconomia e Comunicação, Departamento de Ciências da Informação, Curso de Biblioteconomia, 2010. Trabalho de conclusão de curso, orientado pela Profa. Iara da Conceição Bitencourt Neves.
} 
MACIEL FILHO, Adalberto; AQUINO, Miriam Cunha. As bibliotecas escolares e públicas dos municípios mais industrializados de Pernambuco: uma visão comparativa. Cadernos de Estudos Sociais, Recife, v. 17, n. 2, p. 295-312, 2001. Disponível em: <http://www.fundaj.gov.br/licitacao/bibliotecasescolares.pdf>. Acesso em: 16 out. 2011.

MADUREIRA, Maria Aparecida Ehlke. A biblioteca escolar na rede estadual de ensino de $1^{\circ}$ grau do Paraná: diagnóstico e avaliação. 1985. 132 f. Dissertação (Mestrado em Biblioteconomia) - Departamento de Pós-Graduação em Biblioteconomia, PUC, Campinas, 1885.

MARTINS, Maria da Glória. Bibliotecas escolares de João Pessoa: um estudo contrastivo a nível de escolas públicas e particulares. 1983. 79 f. Dissertação (Mestrado em Biblioteconomia) - Curso de Mestrado em Biblioteconomia, UFPB, João Pessoa, 1983.

MARTINS, Monique da Costa. Perfil das Bibliotecas Escolares da Rede Municipal de Ensino de São José dos Pinhais (PR). In: CONGRESSO BRASILEIRO DE BIBLIOTECONOMIA, DOCUMENTAÇÃO E CIÊNCIA DA INFORMAÇÃO, 24., 2011, Maceió. Sistemas de Informação, Multiculturalidade e Inclusão Social. Maceió: FEBAB, 2011. Disponível em: <http://www.febab.org.br/congressos/index.php/cbbd/xxiv/paper/view/515>. Acesso em: 16 out. 2011.

MARTUCCI, Elisabeth Márcia; MILANI, Maria Regina. Diagnóstico das bibliotecas escolares da rede estadual do município de São Carlos. Informação \& Informação, Londrina, v. 4, n. 2, p. 79-94, 1999. Disponível em:

<http://www.uel.br/revistas/uel/index.php/informacao/article/view/1652/1404>. Acesso em: 16. out. 2011.

MAYRINK, Paulo Tarcísio. A biblioteca escolar brasileira: da caracterização teóricoadministrativa ao estabelecimento de diretrizes e padrões para sua organização e planejamento. 1991. 193f. Tese (Doutorado em Educação) - Faculdade de Educação, USP, São Paulo, 1991.

NASCIMENTO, Aline Mendes; CASTRO FILHO, Cláudio Marcondes. Retrato das bibliotecas escolares da Rede Estadual de Ensino do Município de Ribeirão Preto - SP. Biblionline, João Pessoa, v. 3, n. 1, 2007. Disponível em:

<http://www.ies.ufpb.br/ojs2/index.php/biblio/article/viewFile/1496/1157>. Acesso em: 16 out. 2011.

PERUCCHI, Valmira. A importância da Biblioteca nas Escolas Públicas Municipais de Criciúma - Santa Catarina. Revista ACB: Biblioteconomia em Santa Catarina, Florianópolis, v. 4, n. 4, p. 80-97, 1999.

QUEIROZ, Raimunda Augusta de. Recursos de biblioteca das escolas de $\mathbf{1}^{\mathbf{0}}$ e $\mathbf{2}^{\mathbf{o}}$ graus da rede de ensino da região da Grande Vitória: diagnóstico da situação. 1985. 134 f. Dissertação (Mestrado em Biblioteconomia)-Escola de Biblioteconomia, UFMG, Belo Horizonte, 1985. 